\title{
Temperature-Dependent Simultaneous Ligand Binding in Human Serum Albumin
}

\author{
Sudarson Sekhar Sinha, Rajib Kumar Mitra, and Samir Kumar Pal* \\ Unit for Nano Science and Technology, Department of Chemical, Biological and Macromolecular Sciences, \\ S. N. Bose National Centre for Basic Sciences, Block JD, Sector III, Salt Lake, Kolkata 700 098, India
}

Received: October 8, 2007; In Final Form: February 20, 2008

\begin{abstract}
Human serum albumin (HSA) is a soluble protein in our circulatory system, which is known to bind a variety of drugs and ligands. Since Sudlow's pioneering works on the ligand-binding sites, a major effort of the biophysical/biochemical research has been directed to characterize the structural, functional, and dynamical properties of this protein. Structural studies on HSA have revealed distinct temperature-induced folded states. Despite knowing about the ligand-binding properties and residues important for the binding, less is understood about the temperature-dependent molecular recognition of the protein. Here, we have prepared thermally induced unfolded states of the protein and characterized those by circular dichroism (CD) and differential thermal analysis (DTA) techniques. The change in the globular structure of the protein as a consequence of thermal unfolding has also been characterized by dynamic light scattering (DLS) measurements. We have used two fluorescent ligands (4-(dicyanomethylene)-2-methyl-6-(p-dimethylaminostyryl) 4H-pyran) (DCM; hydrophobic; neutral) and Nile blue (NB; cationic) of different natures to characterize the ligand-binding properties of the protein in the native and thermally unfolded states. The possible binding sites of the ligands have been characterized by competitive binding with other drug molecules having definite binding sites in HSA. Picosecond-resolved Förster resonance energy transfer (FRET) studies along with steady-state and polarization-gated spectroscopies on the ligands in the protein reveal the dynamics of the binding sites at various temperatures. From the FRET studies, an attempt has been made to characterize the simultaneous binding of the two ligands in various temperature-dependent folded states of HSA.
\end{abstract}

\section{Introduction}

The interaction of drugs/ligands with human serum albumin (HSA) (Scheme 1), a carrier of drugs in our circulatory system, is important in the discovery of new drugs as strong binding of the drugs with HSA may reduce bioavailability and increase the in vivo half-life of the drugs. ${ }^{1}$ Since Sudlow et al.'s pioneering work ${ }^{2,3}$ in the mid-1970s on the major drug binding sites of HSA, a significant effort in biophysical research has been directed to examine the structure, stability, and unfolding pathway of unlabeled HSA in solution. ${ }^{4-14}$ In this regard a variety of techniques have been applied, including NMR (nuclear magnetic resonance), ${ }^{15} \mathrm{CD}$ (circular dichroism), ${ }^{10} \mathrm{DSC}$ (differential scanning calorimetry), ${ }^{7-9}$ densiometric and acoustic measurements, ${ }^{14}$ and measurements of intrinsic fluorescence. ${ }^{7,13}$ In addition, there are recent reports in which the steady-state and time-resolved fluorescence of extrinsic fluorophores have been used to explore thermal and chemical denaturation pathways. ${ }^{16-18}$ The interaction of small ligands with the protein has also been explored by using femtosecond-resolved fluorescence spectroscopy. ${ }^{19,20}$ One of the early studies ${ }^{17}$ on the covalently labeled HSA concluded that thermal denaturation of the protein follows multiple steps: native $(\mathrm{N}) \rightarrow$ extended (E) $\rightarrow$ intermediate $(\mathrm{I}) \rightarrow$ unfolded $(\mathrm{U})$. The study reveals that in the extended form at $<50{ }^{\circ} \mathrm{C}$, domains II and I move apart. In the intermediate state above $60{ }^{\circ} \mathrm{C}$, domain II melts (unfolds) but domain I remains intact. Our earlier study ${ }^{14}$ involving densiometric and acoustic measurements also confirms this. Understanding of the recognition of small drugs/ligands by

* Corresponding author. E-mail: skpal@bose.res.in. Fax: 91332335 3477 . biomacromolecules (e.g., proteins) is an important field of investigation. Simultaneous binding of the drugs to a single protein molecule is a complex situation in which the protein recognizes individual drugs by specific and nonspecific interactions. This recognition is in turn strongly dependent on the microenvironment of the protein as it unfolds or refolds. In physiological condition the protein can experience various environments like low or high $\mathrm{pH}$, varying ionic strength, etc., which can induce considerable changes in the native protein structure. Under such a condition how the protein recognizes different drug/ligand molecules is a challenging field of investigation. Different unfolded states in HSA due to various chemical environments in the physiological conditions can also be generated thermally. ${ }^{14,17}$ Moreover, recent advancement in the field of nanoscience requires the preparation of bioactive nanoparticles under different temperatures using protein molecules as templates. ${ }^{21-23}$ Our present study is focused on the generation of different temperature-induced unfolded states of HSA and study of the recognition mechanism of the protein in these states.

In order to study the ligand binding of HSA we have used DCM (4-(dicyanomethylene)-2-methyl-6-( $p$-dimethylaminostyryl) $4 \mathrm{H}-$ pyran) and Nile blue (NB) as model ligands. DCM is a neutral and extremely hydrophobic ligand (Scheme 2), which is completely insoluble in bulk water. On the other hand, NB is cationic in nature with a hydrophobic moiety (Scheme 2). It is completely soluble in water and is a well-known DNA binding dye. ${ }^{24,25}$ A significant spectral overlap of DCM (donor) emission with the absorption of NB (acceptor) offers the Förster resonance energy transfer (FRET) technique to explore the interligand distance in the protein. In the present study, the binding sites 
SCHEME 1: Structure of the Protein Human Serum Albumin (HSA) Indicating Different Domains Present

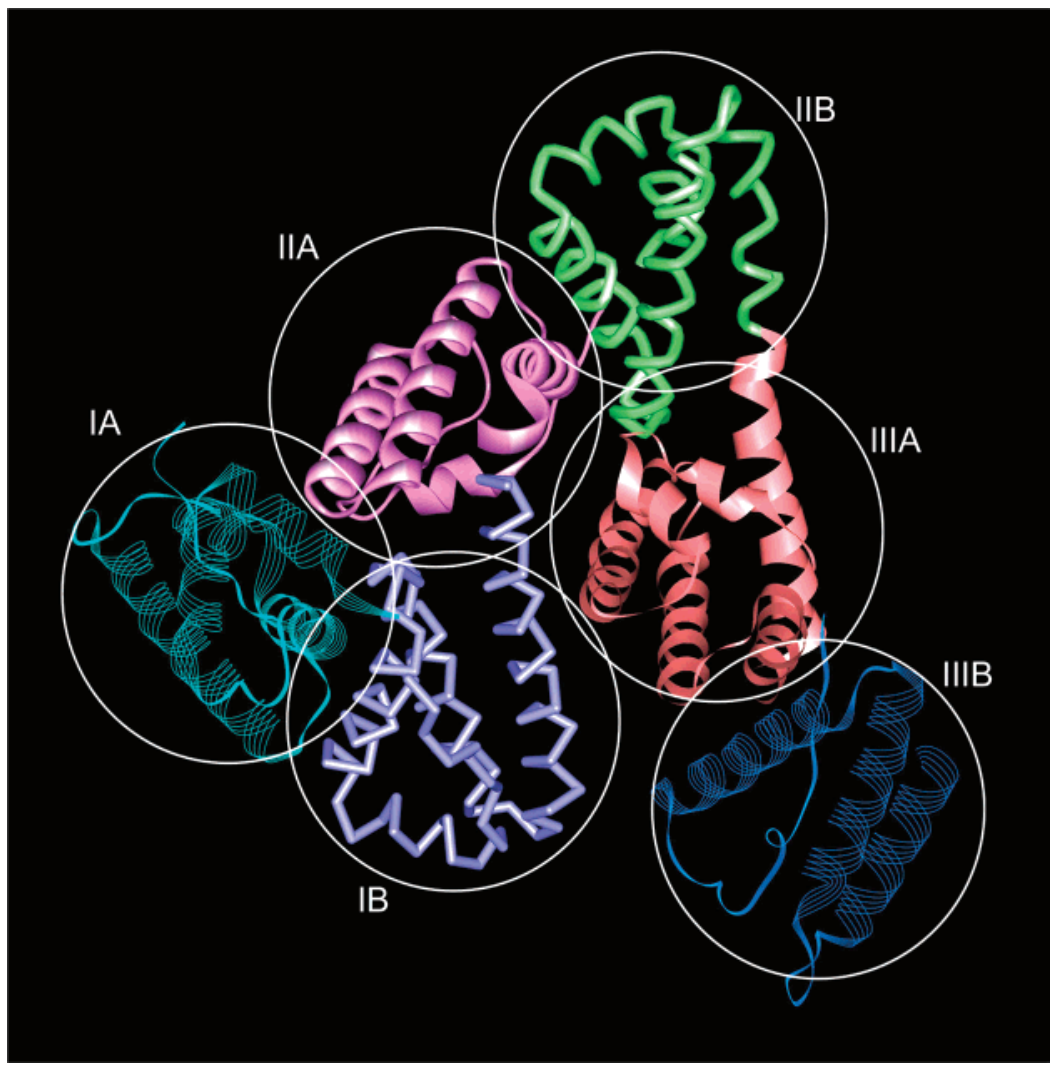

of the model ligands have been identified by studying the competitive binding of the ligands with other drugs having definite binding sites in HSA. Picosecond-resolved fluorescence and polarization-gated anisotropy techniques have been used to characterize the binding sites of the two ligands (DCM, NB). The temperature-dependent time-resolved fluorescence experiments on the two ligands in the protein explore the nature of binding at various unfolded states of HSA. The environmental relaxation dynamics of the DCM binding sites at various temperatures is also investigated through time-resolved solvation dynamics. The temperature-dependent structural evolution has been followed by CD, differential thermal analysis (DTA), and dynamic light scattering (DLS) experiments. The knowledge of interligand distances in the protein as measured by FRET at various temperatures and the chemical nature of the ligands also intuits the possible locations of the ligands in the different folded states of the protein.

\section{Materials and Methods}

Human serum albumin, NB, warfarin, diflunisal, 3,5-diiodosalicylic acid (DiISA), and phosphate buffer are obtained from Sigma. The fluorescent probe DCM is from Exciton. The sample solutions were prepared in $50 \mathrm{mM}$ phosphate buffer $(\mathrm{pH}=7.0)$ using water from a Millipore system. The DCM-protein solutions were prepared by injecting concentrated ethanolic probe solution into the aqueous protein solutions and mixing by continuous stirring for $1 \mathrm{~h}$. The probe-protein mixtures were dialyzed against phosphate buffer to expel free probes from the solution. NB-protein complex is prepared by mixing a measured amount of protein with NB solution of known concentration followed by vigorous stirring for $1 \mathrm{~h}$. To ensure complete complexation of the probes with the protein, the [probe]/[protein] ratio was maintained at 1:50 for both the probes. To affirm the binding sites of the fluorophores (DCM and NB), we studied the competitive binding of the fluorophores with drugs, whose definite binding sites in the protein are known. The drugs, warfarin, diflunisal, and DiISA (Scheme 2), used for the competitive binding study bind in different domains of HSA as evidenced from recent X-ray crystallographic study. ${ }^{26}$ Small amounts of the drugs were added in $2 \mathrm{~mL}$ of DCM-HSA (or NB-HSA) solutions followed by stirring for at least $3 \mathrm{~h}$. The supernatant of the solution was taken for the steady-state and time-resolved measurements. For the energy transfer experiment, $\mathrm{NB}$ (acceptor) concentration was maintained to be similar to that of the protein in the solution. DLS and DTA studies were carried out using $200 \mu \mathrm{M}$ HSA solution. CD studies were done with $1.5 \mu \mathrm{M}$ protein solution in $0.4 \mathrm{~cm}$ path length cell. Experimental details are described in the Supporting Information.

Solvation correlation function, $C(t)$, was constructed by following the equation: ${ }^{27,28}$

$$
C(t)=\frac{v(t)-v(\infty)}{v(0)-v(\infty)}
$$

where $v(0), v(\mathrm{t})$, and $v(\infty)$ stand for the wavenumber $\left(\right.$ in $\mathrm{cm}^{-1}$ ) at the emission maximum at time zero, $t$, and infinity, respectively. For anisotropy $(r(t))$ measurements, emission polarization was adjusted to be parallel or perpendicular to that of the excitation, and anisotropy is defined as

$$
r(t)=\frac{\left[I_{\text {para }}-G I_{\text {perp }}\right]}{\left[I_{\text {para }}+2 G I_{\text {perp }}\right]}
$$

where $I_{\text {para }}$ and $I_{\text {perp }}$ are the emission intensities when the polarization is parallel and perpendicular to the excitation, respectively. $G$, the grating factor, was determined by following the long time tail matching technique. ${ }^{29}$ We estimated the 
SCHEME 2: Molecular Structure of the Probe Ligands, DCM and NB, and Drugs Warfarin, Diflunisal, and 3,5Diiodosalicylic Acid<smiles>CC[N+](Cl)=c1ccc2nc3c(cc(N)c4ccccc43)oc-2c1</smiles>

Nile blue<smiles>CC1=CC(=C(C#N)C#N)C=C(/C=C/c2ccc(N(C)C)cc2)O1</smiles>

3,5-diiodosalicylic acid<smiles>O=C(O)c1cc(-c2ccc(F)cc2F)ccc1O</smiles>

Diflunisal<smiles>CC(=O)CC(c1ccccc1)c1c(O)oc2ccccc2c1=O</smiles>

Warfarin

fluorescence resonance energy transfer efficiency of the donor (DCM) to the acceptor (NB) and therefrom calculated the distance of the donor-acceptor pairs $(R)$ by using the formula ${ }^{30}$ $R^{6}=\left[R_{0}{ }^{6}(1-E)\right] / E$, where $R_{0}$ is the Förster distance and $E$ is the efficiency of energy transfer given by $E=1-\left(\tau_{\mathrm{DA}} / \tau_{\mathrm{D}}\right)$, where $\tau_{\mathrm{D}}$ is the lifetime of the donor in the absence and $\tau_{\mathrm{DA}}$ is that in the presence of the acceptor. ${ }^{30}$ A detailed description of the methods used can be found in the Supporting Information.

\section{Results and Discussion}

A. Characterization of the Thermally Unfolded States of HSA. Unfolding of a protein is usually marked by a change in the secondary and globular structure of the protein. The change in the globular structure of a protein can be studied by DLS measurements. The inset of Figure 1a shows the change in the globular structure of the protein at the temperatures of 25 and $75^{\circ} \mathrm{C}$. The figure also shows that the hydrodynamic diameter of the protein increases from $10.1 \mathrm{~nm}$ in the native state at $25^{\circ} \mathrm{C}$ to $38.7 \mathrm{~nm}$ at $75{ }^{\circ} \mathrm{C}$, indicating that the protein undergoes a considerable change in its native globular structure due to thermal unfolding. It is seen that the curve showing the hydrodynamic diameter of the protein against temperature has two points of discontinuity (as evidenced from the change in slope). These discontinuities reveal that the unfolding of the protein takes place involving at least two intermediate unfolded states at two consecutive temperatures of 63 and $79{ }^{\circ} \mathrm{C}$, respectively. The secondary structure of the protein also undergoes changes with increase in temperature.
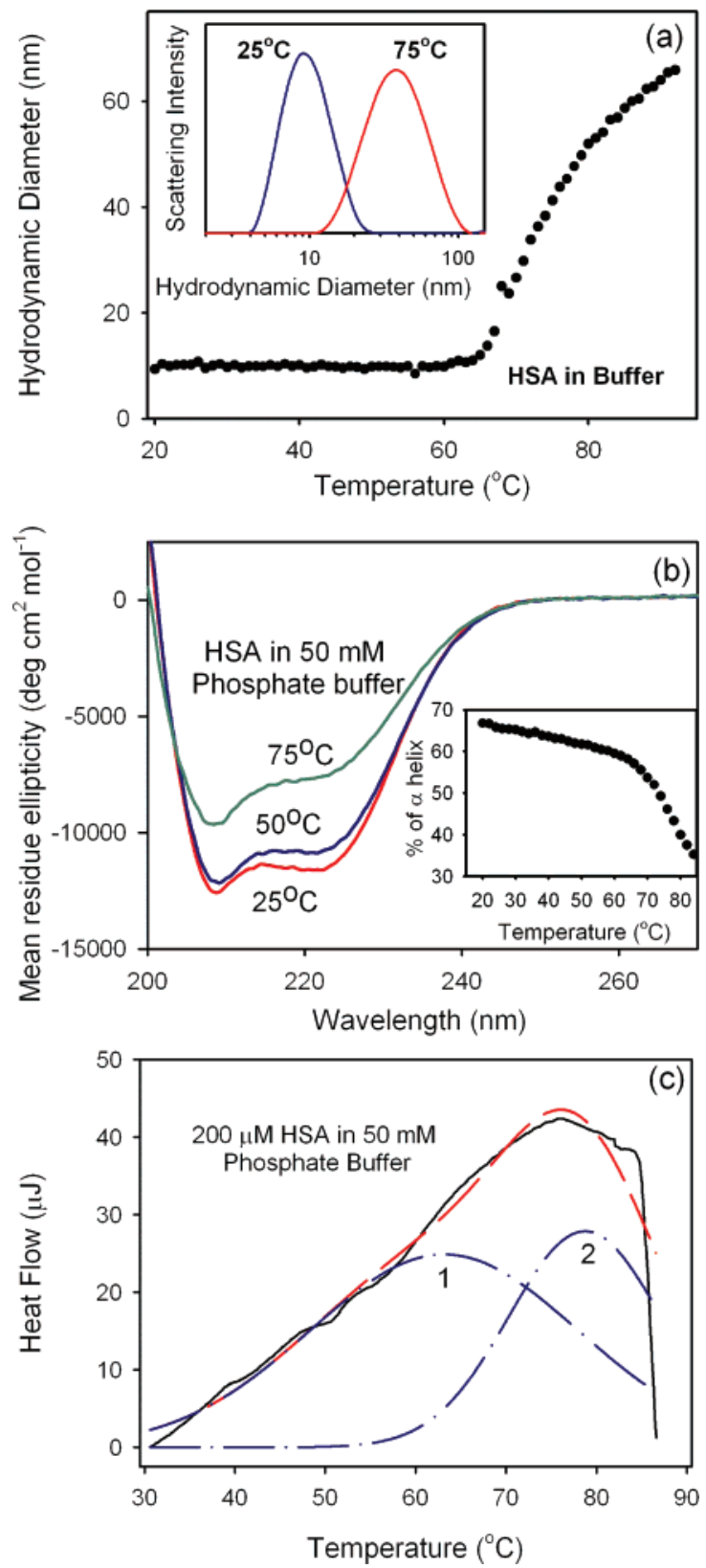

Figure 1. (a) Change in the hydrodynamic diameter of $200 \mu \mathrm{M}$ HSA in $50 \mathrm{mM}$ phosphate buffer as a function of temperature. The inset shows the dynamic light scattering (DLS) profiles of the same sample at 25 and $75{ }^{\circ} \mathrm{C}$. (b) CD spectra of HSA in $50 \mathrm{mM}$ phosphate buffer at three different temperatures. The inset shows the percentage of $\alpha$-helix content in HSA as a function of temperature. (c) Differential thermal analysis (DTA) curve of $200 \mu \mathrm{M}$ HSA in $50 \mathrm{mM}$ phosphate buffer. The two blue lines (1 and 2) correspond to the deconvoluted curves peaking at 63.1 and $77.8^{\circ} \mathrm{C}$, respectively. The solid line is the experimental DTA curve, and the dotted red line is the best-fitted overall curve corresponding to the two convoluted curves 1 and 2 .

The existence of intermediates in the thermal unfolding pathway of a protein can also be evidenced from the changes in its secondary structure. Figure $1 \mathrm{~b}$ shows the change in the mean residue ellipticity of the protein at temperatures of 25 , 50 , and $75{ }^{\circ} \mathrm{C}$, respectively, as obtained from $\mathrm{CD}$ experiments. The percentage of $\alpha$-helix in the protein, indicated by the negative peaks at 208 and $222 \mathrm{~nm}$, decreases from $65 \%$ in the native state at $25{ }^{\circ} \mathrm{C}$ to $62 \%$ at $50{ }^{\circ} \mathrm{C}$ and $46 \%$ at $75{ }^{\circ} \mathrm{C}$. This shows that the protein loses a considerable fraction of its secondary structure during thermal denaturation. The decrease in the percentage of $\alpha$-helix is shown as a function of 

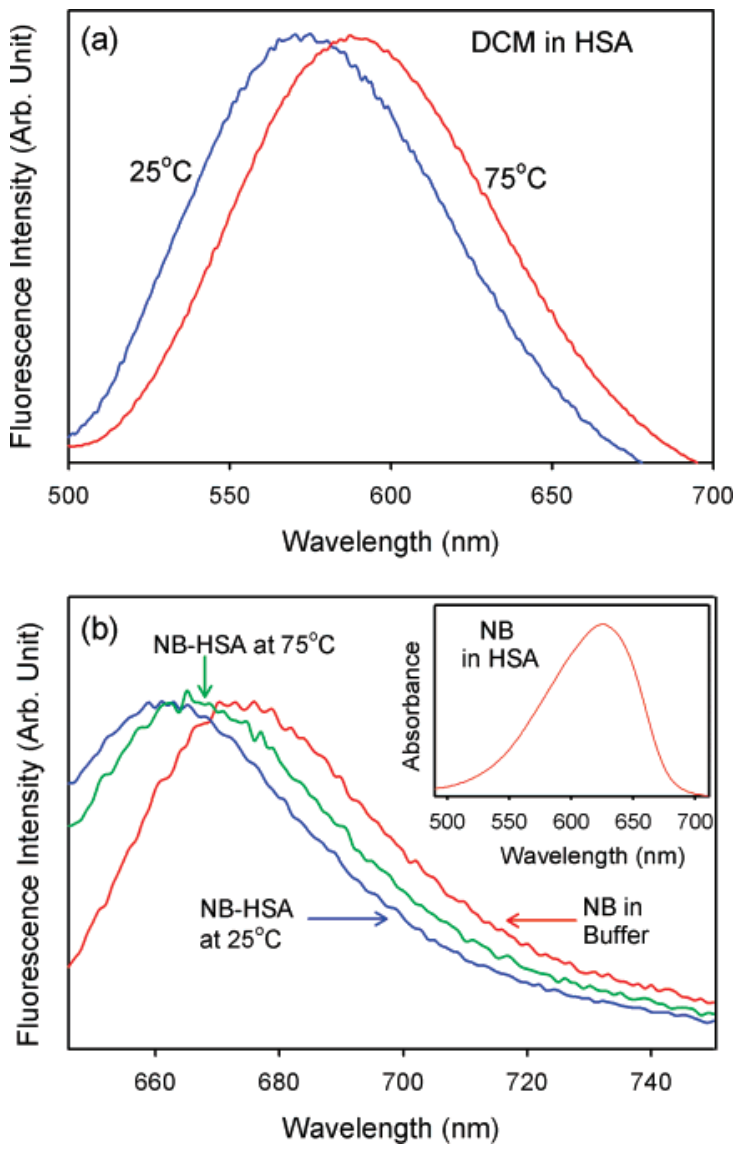

Figure 2. (a) Normalized steady-state fluorescence spectra of DCM in HSA at 25 and $75{ }^{\circ} \mathrm{C}$. (b) Normalized steady-state fluorescence spectra of NB in $50 \mathrm{mM}$ phosphate buffer and HSA at 25 and $75^{\circ} \mathrm{C}$. The absorption spectrum of NB in HSA is shown in the inset.

temperature in the inset of Figure 1b, and the profile is consistent with the earlier report. ${ }^{31}$ The plot also shows that the decrease in the percentage helicity with temperature is discontinuous and associated with at least two points of discontinuities, at temperatures of 63 and $78{ }^{\circ} \mathrm{C}$, respectively, indicating the existence of intermediates in the thermal unfolding pathway. It is to be noted that the presence of intermediate unfolded states in the thermal and chemical denaturation of bovine serum albumin (BSA), which is structurally similar to HSA, has already been indicated by calorimetric ${ }^{32}$ studies.

The thermal unfolding process of HSA has also been studied by the DTA method. The denaturation process can be described as an interchange between the native and unfolded states. Figure 1c represents the DTA profile of $200 \mu \mathrm{M}$ HSA in $50 \mathrm{mM}$ phosphate buffer. The area under the endothermic curve stands for the enthalpy change associated with the unfolding process $\left(\Delta H_{\mathrm{U}}\right)$. The peaks in the exothermic region have been neglected as they might emanate from the aggregation of HSA molecules. It has previously been reported by $\mathrm{Pico}^{9}$ that the midpoint temperature of unfolding of HSA, as obtained by DSC is $63.1^{\circ} \mathrm{C}$ at $\mathrm{pH}$ 7.4. We herein carry out the DTA measurement up to $90{ }^{\circ} \mathrm{C}$ (Figure 1c). To compare our results with those obtained by Pico, ${ }^{9}$ we deconvolute the curve into two peaking at 63.1 and $77.8{ }^{\circ} \mathrm{C}$. The positions of the peaks correspond to the temperature-induced structural intermediates of the protein. This observation is also consistent with that observed in the DLS (Figure 1a) measurement.

B. Spectroscopic Investigation of the Ligands Bound to HSA. Figure 2 shows steady-state emission spectra of the probe ligands DCM (Figure 2a) and NB (Figure 2b) in HSA at various
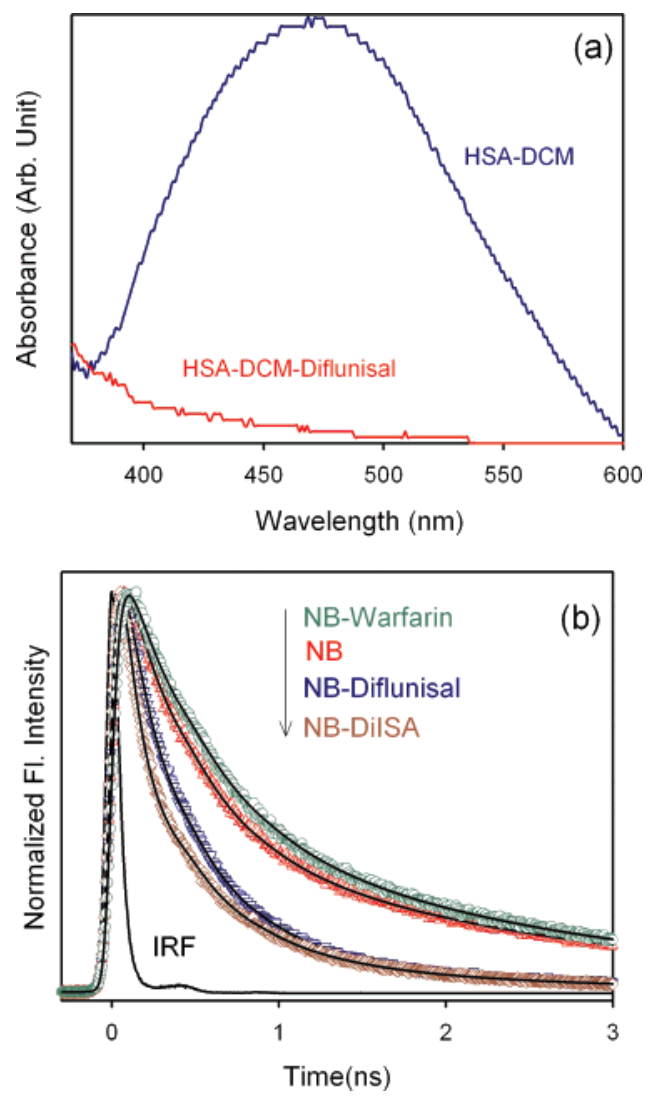

Figure 3. (a) Normalized steady-state absorption spectra of DCMHSA in the presence and absence of diflunisal at $25^{\circ} \mathrm{C}$. (b) Timeresolved normalized fluorescence transients of NB-HSA, in the presence of diflunisal, 3,5-diiodosalicylic acid (DiISA), and warfarin.

temperatures. We have performed our studies at three different temperatures of 25,50 , and $75^{\circ} \mathrm{C}$, and the spectra are shown at two extreme temperatures for clarity. As shown in Figure $2 \mathrm{a}$ the emission spectrum of DCM in HSA (peak at $575 \mathrm{~nm}$ ) at $25^{\circ} \mathrm{C}$ is consistent with its location in a hydrophobic cavity of the protein (emission peaks of DCM in polar methanol and nonpolar $n$-heptane are 625 and $530 \mathrm{~nm}$, respectively $\left.{ }^{33}\right)$. It should be noted that DCM is extremely hydrophobic and completely insoluble in water and one of the possible locations of the probe is expected to be in the domain IIIA. ${ }^{6}$ To confirm this, we study the competitive binding of DCM with diflunisal, which has an affinity to bind in domain IIIA of HSA. ${ }^{26}$ Figure 3 a shows the absorption spectra of DCM-HSA in the absence and in the presence of diflunisal. In the presence of diflunisal, DCM is expelled out of its binding site and gets precipitated out due to its insolubility in water (orange precipitation at the bottom of the vessel) resulting in a decrease in the absorbance at $470 \mathrm{~nm}$, confirming the binding of DCM in domain IIIA of HSA. Figure $2 \mathrm{a}$ also shows a red shift (to $585 \mathrm{~nm}$ ) in the DCM emission at higher temperatures, indicating a more polar environment experienced by the probe at $75^{\circ} \mathrm{C}$. The observation is consistent with the fact that, at higher temperature, HSA swells up (Figure 1a) and accommodates more labile water molecules in its cavity. ${ }^{14}$ The emission of the ligand NB (Figure $2 \mathrm{~b}$ ) also shows similar behavior at various temperatures. NB in buffer produces an emission peak at $674 \mathrm{~nm}$ at $25{ }^{\circ} \mathrm{C}$, which does not change considerably as the temperature is raised. From the temperature-dependent emission spectra of $\mathrm{NB}$ as evidenced in Figure $2 b$, it is clear that the environment of NB in HSA also becomes more polar at higher temperature. The inset of Figure $2 b$ shows the absorption of NB in HSA, which does not change with temperature. NB is a cationic dye with a large 

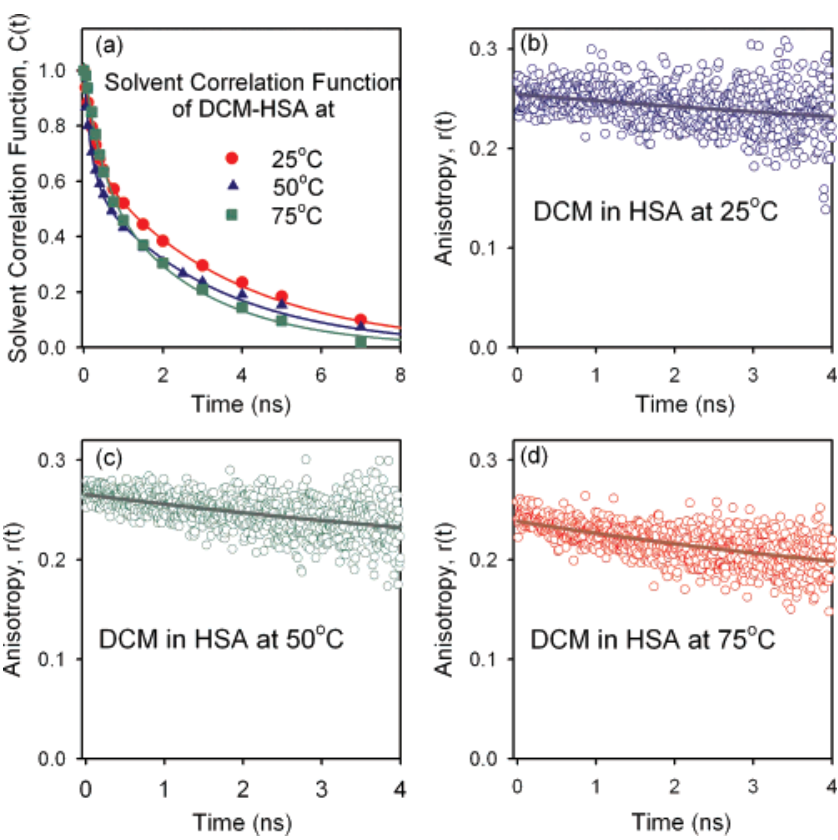

Figure 4. (a) Solvent correlation function, $C(t)$, of HSA-bound DCM in $50 \mathrm{mM}$ phosphate buffer at different temperatures. Time-resolved anisotropy, $r(t)$, of HSA-bound DCM in $50 \mathrm{mM}$ phosphate buffer at (b) 25 , (c) 50 , and (d) $75^{\circ} \mathrm{C}$.

hydrophobic moiety (Scheme 2). Distinct binding sites for the cationic dyes in HSA are not clearly documented in the present literature. Early studies ${ }^{34,35}$ on the binding of cationic surfactants with a hydrophobic alkyl chain explored the possible locations of the surfactants in the Sudlow I and Sudlow II regions ${ }^{35}$ which are close to domains II and III, respectively. Our FRET experiments on the DCM-NB pair in HSA suggest a possible location of NB in domain IIB at room temperature (see below) as also confirmed from the competitive binding experiments. From Figure $3 b$ it is clear that the lifetime of NB in HSA decreases in the presence of diflunisal and DiISA, whereas insignificant change is observed in the presence of warfarin. The first two drugs bind in both the domains IIA and IIB, whereas warfarin explicitly binds in domain IIA. It is evident from the figure that in the presence of diflunisal and DiISA, the fluorescence decay of NB becomes faster indicating expulsion of the probe from its binding site. These observations are consistent with the binding of NB in the IIB subdomain of HSA.

In order to investigate the nature of dynamics of the local environment of DCM in HSA at different temperatures, we have studied the solvation relaxation of the probe in HSA at different temperatures. DCM is a well-known solvation probe for proteins $^{36}$ and micellar systems..$^{33,37}$ The constructed temperature-dependent solvent correlation functions are shown in Figure $4 \mathrm{a}$, and the numerical fitting parameters are summarized in Table 1. At room temperature the correlation function shows a biexponential decay with time constants of 0.3 and $3.8 \mathrm{~ns}$. The faster time constant of $0.3 \mathrm{~ns}$ is consistent with the rigidly trapped water molecules in the cavity, ${ }^{16}$ and the relatively longer time constant of $3.8 \mathrm{~ns}$ is the reflection of the relaxation of the excited state of the probe by polar residues of the protein. ${ }^{38} \mathrm{At}$ higher temperature the overall solvation dynamics of the probe becomes faster, which is consistent with the fact that labile water molecules enter into the cavity of the protein at elevated temperatures. ${ }^{14}$ At $50{ }^{\circ} \mathrm{C}$, as the protein unfolds water molecules can intrude into the cavity of HSA resulting in an increase in the faster component. The physical motion of the probe DCM in the HSA cavity is reflected in the temporal decays of the fluorescence anisotropy at different temperatures (Figure $4 b-$

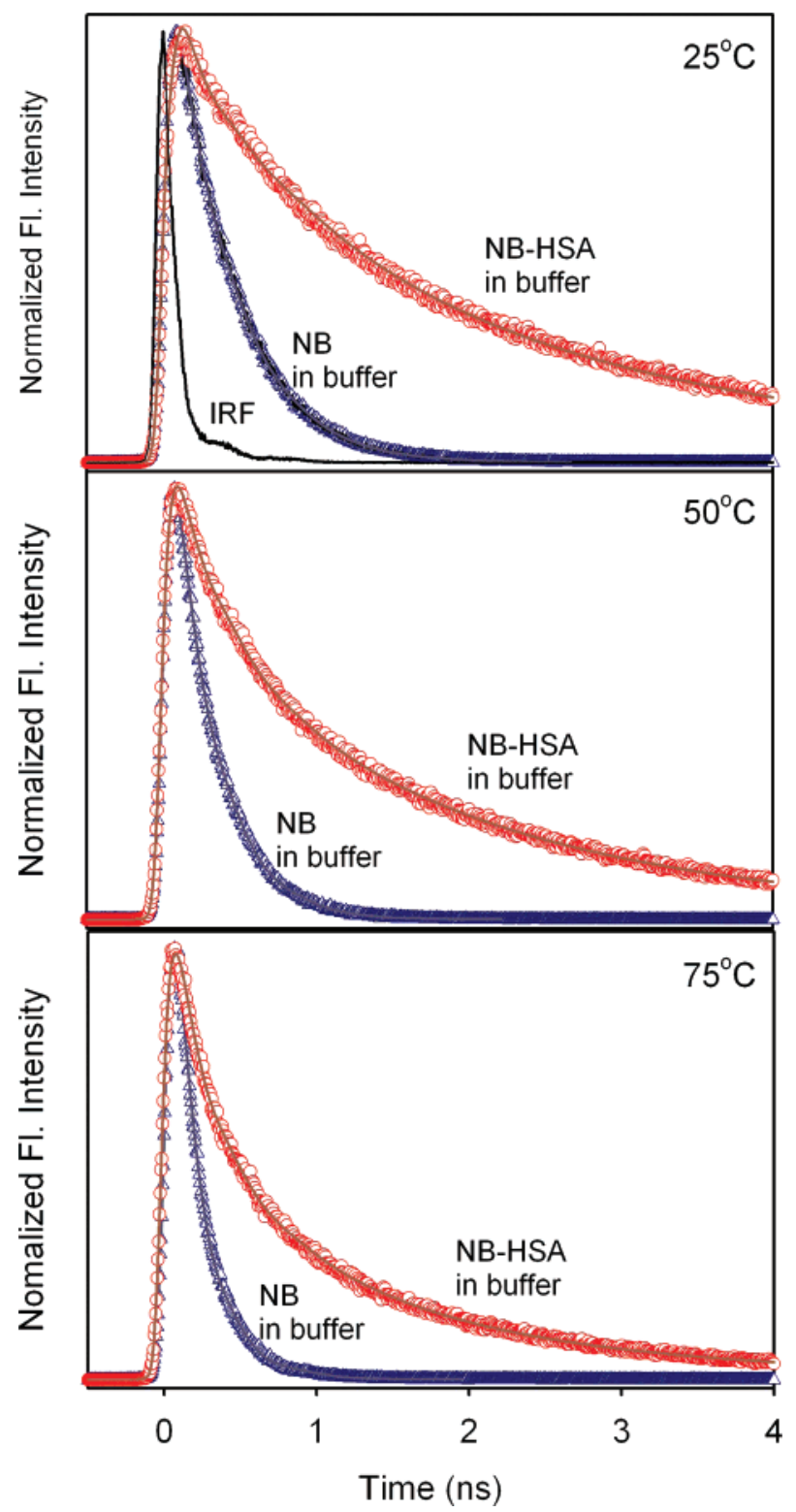

Figure 5. Time-resolved normalized fluorescence transients of $2 \mu \mathrm{M}$ NB in $50 \mathrm{mM}$ phosphate buffer in the absence and presence of 100 $\mu \mathrm{M}$ HSA at 25,50 , and $75^{\circ} \mathrm{C}$.

TABLE 1: Time-Dependent Solvation and Anisotropy of DCM in HSA

\begin{tabular}{ccc}
\hline \multicolumn{3}{c}{ Solvation Correlation Function, $C(t)$} \\
\hline $\begin{array}{c}\text { temperature } \\
\left({ }^{\circ} \mathrm{C}\right)\end{array}$ & $\tau_{1}(\mathrm{~ns})^{a}$ & $\tau_{2}(\mathrm{~ns})$ \\
\hline 25 & $0.30(34 \%)$ & $3.8(66 \%)$ \\
50 & $0.25(41 \%)$ & $3.5(59 \%)$ \\
75 & $0.40(42 \%)$ & $2.6(58 \%)$ \\
\multicolumn{3}{c}{ Rotational Anisotropy, $r(t)$} \\
\hline
\end{tabular}

\begin{tabular}{cccc}
\hline $\begin{array}{c}\text { temperature } \\
\left({ }^{\circ} \mathrm{C}\right)\end{array}$ & $r_{0}{ }^{b}$ & offset & $\tau_{\text {rot }}(\mathrm{ns})^{c}$ \\
\hline 25 & 0.25 & 0.18 & 10.9 \\
50 & 0.26 & 0.17 & 9.50 \\
75 & 0.26 & 0.15 & 8.00
\end{tabular}

${ }^{a} \tau$ represents time constant. ${ }^{b} r_{0}$ is the rotational anisotropy at zero time. ${ }^{c} \tau_{\text {rot }}$ is the rotational time constant.

d). The numerical fitting is summarized in Table 1 . The decay at room temperature (Figure $4 \mathrm{~b}$ ) shows a time constant of 11 ns, indicating the tumbling motion of the probe in the 
TABLE 2: Time-Dependent Fluorescence Decay Constants and Anisotropy of NB

\begin{tabular}{|c|c|c|c|c|c|c|}
\hline \multicolumn{7}{|c|}{ Time-Resolved Fluorescence Decay } \\
\hline \multirow[b]{2}{*}{$\begin{array}{l}\text { temperature } \\
\qquad\left({ }^{\circ} \mathrm{C}\right)\end{array}$} & \multirow{2}{*}{$\frac{\text { in buffer }}{\tau} \frac{}{(\mathrm{ns})^{a}}$} & \multicolumn{5}{|c|}{ in HSA } \\
\hline & & \multicolumn{2}{|c|}{$\begin{array}{c}\tau_{1} \\
(\mathrm{~ns})\end{array}$} & $\begin{array}{c}\tau_{2} \\
(\mathrm{~ns})\end{array}$ & \multicolumn{2}{|r|}{$\begin{array}{c}\tau_{3} \\
(\mathrm{~ns})\end{array}$} \\
\hline 25 & 0.35 & \multicolumn{2}{|c|}{$0.40(30 \%)$} & $2.10(35 \%)$ & \multirow{3}{*}{\multicolumn{2}{|c|}{$\begin{array}{l}3.5(35 \%) \\
2.7(18 \%) \\
1.8(20 \%)\end{array}$}} \\
\hline 50 & 0.20 & $0.20(5$ & & $1.40(28 \%)$ & & \\
\hline 75 & 0.15 & $0.15(5$ & & $0.50(23 \%)$ & & \\
\hline \multicolumn{7}{|c|}{ Rotational Anisotropy, $r(t)$} \\
\hline & in buffer & \multicolumn{5}{|c|}{ in HSA } \\
\hline $\begin{array}{l}\text { temperature } \\
\qquad\left({ }^{\circ} \mathrm{C}\right)\end{array}$ & $\begin{array}{c}\tau_{\text {rot }} \\
(\mathrm{ns})^{b}\end{array}$ & $r_{0}{ }^{c}$ & $\begin{array}{c}\tau_{1} \\
\text { (ns) }\end{array}$ & $\beta_{1}{ }^{d}$ & $\begin{array}{c}\tau_{2} \\
\text { (ns) }\end{array}$ & $\beta_{2}$ \\
\hline 25 & 0.15 & 0.39 & 0.50 & 0.20 & 6.00 & 0.27 \\
\hline 50 & 0.10 & 0.40 & 0.70 & 0.25 & 5.30 & 0.35 \\
\hline 75 & 0.07 & 0.38 & 0.55 & 0.13 & 3.10 & 1.00 \\
\hline
\end{tabular}

${ }^{a} \tau$ represents time constant. ${ }^{b} \tau_{\text {rot }}$ is the rotational time constant. ${ }^{c} r_{0}$ is the rotational anisotropy at zero time. ${ }^{d} \beta$ is the measure of the extent to which the emission is depolarized by rotation (see eqs 4 and 5 for details).

hydrophobic moiety of the protein and a large offset value, which does not decay in the experimental time window of 5 ns. The relatively high $\tau_{\text {rot }}$ value at $25^{\circ} \mathrm{C}$ confirms the possible location of DCM deep inside the hydrophobic cavity. The persistence of the anisotropy offset also corroborates well with the global tumbling motion of the protein in buffer which has a time constant of the order of 50 ns. ${ }^{38,39}$ Similarity of the long time constant (offset) of the anisotropy decay at elevated temperatures with that at room temperature reveals that the increase in $d_{\mathrm{H}}$ of $\mathrm{HSA}$ at $75{ }^{\circ} \mathrm{C}$ (Figure 1a) is not due to aggregation of the protein. At higher temperatures, the time constants become faster, which might be due to the penetration of water into the DCM binding site of HSA (domain IIIA) at elevated temperatures. The observation is consistent with higher polarity in the binding site of DCM at elevated temperature as also evidenced from the emission spectrum (Figure 2a). Moderate change in $\tau_{\text {rot }}$ and the presence of large offset values signify a less perturbed ligand-binding site and rule out the detachment of the ligand DCM from the protein at higher temperatures. The observation is consistent with the fact that the possible binding site of DCM is domain IIIA, which remains unaltered upon thermal denaturation of the protein. ${ }^{26}$

The fluorescence transients of NB in HSA at different temperatures are shown in Figure 5. NB is completely soluble in water, wherein it undergoes ultrafast proton transfer, ${ }^{40,41}$ which considerably quenches its lifetime to $\sim 300$ ps at room temperature. ${ }^{42}$ The slowing down of fluorescence decay of NB in HSA at room temperature compared to that in bulk water (upper panel of Figure 5) is indicative of the attachment of the probe in the protein interior. The time constants from the numerical fitting of the transients are presented in Table 2. It can be observed that at $25^{\circ} \mathrm{C}$ the transient has a time component similar to that of NB in buffer $(0.35 \mathrm{~ns})$, along with two large components of 2.1 and $3.5 \mathrm{~ns}$, indicating that a fraction of NB molecules are in a free state in the bulk buffer and the rest are bound to the protein. The two large components indicate heterogeneity in the location of the probe in the protein. We rationalize the 3.5 and $2.1 \mathrm{~ns}$ components in the NB-HSA at room temperature to be due to the binding of the probe in nonpolar (deep in the cavity) and polar (mouth of the cavity) environments, respectively. Upon thermal denaturation both the time constants become faster implying significant modification in the binding site of NB. Also the relative increase in the

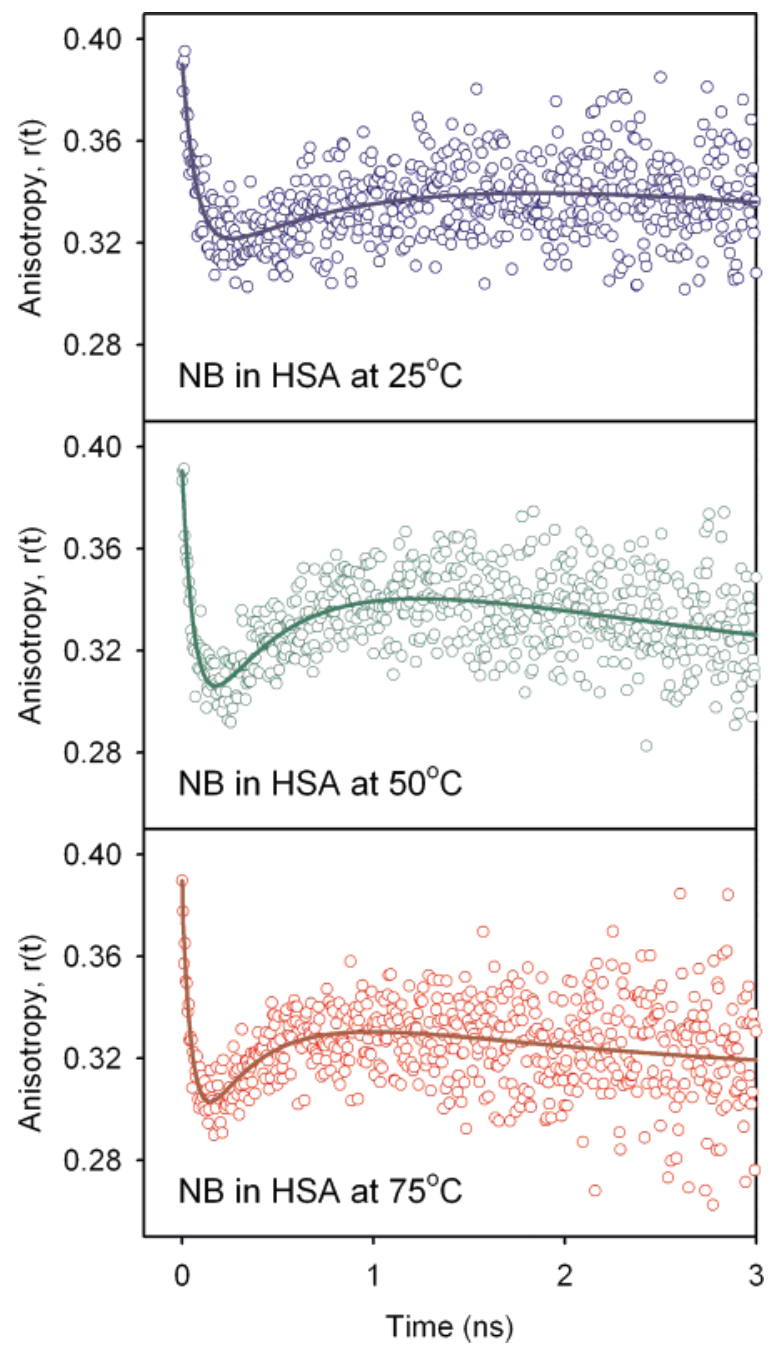

Figure 6. Time-resolved anisotropy, $r(t)$, of $2 \mu \mathrm{M} \mathrm{NB}$ in the presence of $100 \mu \mathrm{M}$ HSA at 25,50 , and $75^{\circ} \mathrm{C}$.

contribution of the faster component $\left(\tau_{1}\right)$ indicates significant partitioning of NB into bulk buffer at higher temperatures.

Figure 6 shows the fluorescence anisotropy of NB in HSA at different temperatures. All the anisotropy transients show an initial faster decay followed by a relatively longer rise component resembling the "dip and rise" shape reported earlier for lipid bilayers and lipid-protein systems ${ }^{43-45}$ Such a behavior reflects the residence of the probe in more than one microenvironments with different fluorescence lifetimes. In such systems, different fluorophore populations may show variation in their dynamic behavior, and hence the measured anisotropy decay should be analyzed after considering contributions from each component.

In the present study, we have analyzed the anisotropy decay using the model developed by Ludescher et al. ${ }^{45}$ and modification of the model made by Das and Mazumdar. ${ }^{46}$ For a fluorophore existing in multiple microenvironments, the fluorescence decay, $I(t)$ can be expressed as

$$
I(t)=\sum_{i=1}^{n} \alpha_{i} I_{i}(t)
$$

where $n$ is the number of distinct microenvironments and $\sum_{i} \alpha_{i}$ $=1$. The fractional intensity, $g_{i}(t)$, due to each component is given by 


$$
g_{i}(t)=\frac{\alpha_{i} I_{i}(t)}{I(t)}
$$

Then the experimental anisotropy decay, $r(t)$, for a heterogeneous system can be expressed as a linear combination of anisotropy decays from all the species,

$$
r(t)=\sum_{i} g_{i}(t) r_{i}(t)
$$

and $r_{i}(t)$ can be written as

$$
r_{i}(t)=\beta_{i} \mathrm{e}^{-t / \tau_{\mathrm{i}}}+\left(1-\beta_{i}\right)
$$

and the corresponding $r(t)$ takes up the form

$$
\begin{array}{r}
r_{i}(t)=r(0)\left[g_{1} \mathrm{e}^{-t / \tau_{\mathrm{w}}}+g_{2}\left\{\beta_{1} \mathrm{e}^{-t / \tau_{1}}+\left(1-\beta_{1}\right)\right\}+\right. \\
\left.g_{3}\left\{\beta_{2} \mathrm{e}^{-t / \tau_{2}}+\left(1-\beta_{2}\right)\right\}\right]
\end{array}
$$

where $\tau_{\mathrm{w}}$ is the rotational time constant of NB in buffer, $\tau_{1}$ and $\tau_{2}$ are the rotational time constants of the dye inside two microenvironments (as evidenced from the fluorescence lifetime measurements) of the protein, and $\beta_{1}$ and $\beta_{2}$ are the measures of the extent to which the emission is depolarized by the rotational components $\tau_{1}$ and $\tau_{2}$, respectively. The fitted parameters are presented in Table 2. It is evident from the table that NB has three distinct locations: in bulk buffer $(\sim 0.1 \mathrm{~ns})$, at the surface and/or in the mouth/entrance of the hydrophobic cavity (demarcated by the smaller time scale of the order of $0.5 \mathrm{~ns}$ ), and deep inside a cavity of the protein (demarcated by the larger time constant of $6 \mathrm{~ns}$ ). The longest time constant is in the order of that of DCM in the HSA cavity (Table 1). With increasing temperature, this time constant decreases markedly, especially at $75{ }^{\circ} \mathrm{C}$, indicating significant change in the host environment. The presence of residual anisotropy stands for the global tumbling motion of the protein in buffer.

C. FRET Measurements. In order to measure the interligand distance between DCM and NB simultaneously bound to the protein, we have used the FRET technique. The significant spectral overlap of DCM emission with the absorption of NB is expected to reveal interligand distance, when they are in close proximity. Figure $7 \mathrm{a}$ shows the normalized DCM (donor) emission and NB (acceptor) absorption in HSA at room temperature. Figure $7 \mathrm{~b}$ shows the emission of the donor and that of the donor-acceptor complex indicating to the fact that emission from the donor gets quenched due to the absorption by the acceptor. This quenching of the donor emission is further evident from the faster donor lifetime of the donor-acceptor (DCM-NB) complex compared to that of the donor (DCM) itself in the protein (Figure 7c). The Förster distance, $R_{0}$, for the system is calculated to be $3.0 \mathrm{~nm}$. Thus, it is expected that similar interligand distance in the protein can be estimated very accurately. The distance between the probes in HSA at room temperature is found to be $3.2 \pm 0.4 \mathrm{~nm}$. It can be noted that the intersubdomain distance between IIB and IIIA is $3.2 \mathrm{~nm}^{6}$ at room temperature. A detailed X-ray crystallographic study ${ }^{6}$ on HSA explored the locations of various kinds of ligand molecules in the different binding sites of the protein. The hydrophobic ligands (e.g., DCM) reside in the domain IIIA $^{6}$ as evidenced from our competitive binding studies. A recent X-ray crystallographic experiment on the binding sites of a number of ligand/drug molecules with HSA clearly demonstrated that the ligand diflunisal, containing two phenyl rings, similar to the DCM molecule, binds to the domain IIIA of the protein. ${ }^{26}$ Since the hydrophobic ligand DCM is located in domain IIIA,
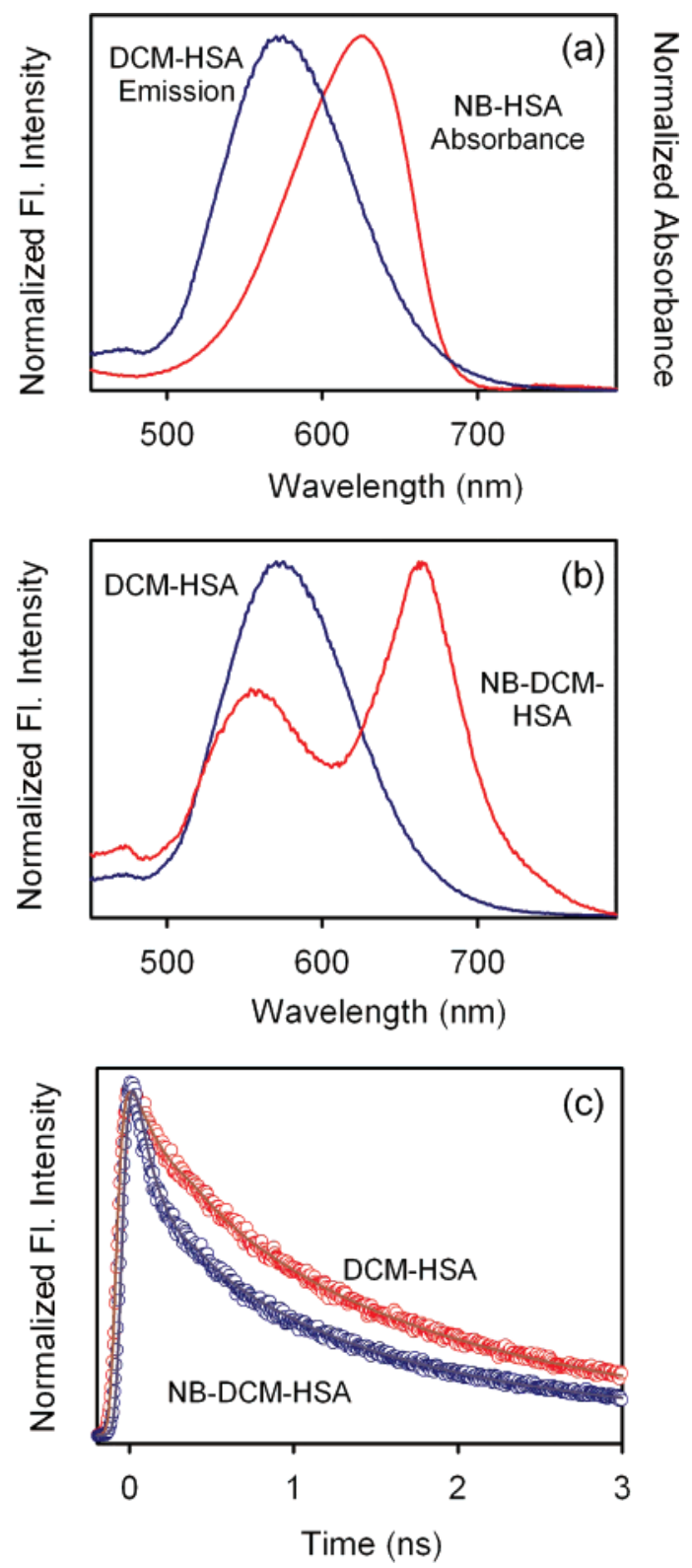

Figure 7. (a) Spectral overlap of the donor (DCM) and acceptor (NB) in HSA at $25^{\circ} \mathrm{C}$. (b) Emission spectrum of HSA-bound DCM in the absence and presence of the acceptor NB at $25^{\circ} \mathrm{C}$. (c) Time-resolved normalized fluorescence transients of HSA-bound DCM in the absence and presence of the acceptor NB at $25^{\circ} \mathrm{C}$.

the measured interligand distance indicates to one of the most probable locations of NB at IIB (Sudlow I region) subdomain. Our competitive binding study also confirms the location of NB in domain IIB.

The significant changes in the excited-state lifetime and anisotropy of the probe NB (Figures 5 and 6) in the protein at higher temperatures indicate a major alteration of the NBbinding domain at elevated temperatures. Also with increase in temperature the ligand-pair distance decreases progressively (Table 3). This observation can be rationalized in terms of the melting of subdomain IIB at higher temperatures, ${ }^{14,17}$ which essentially expels the ligands to bulk-type environment as evidenced in the fluorescence life time measurements (Figure 5 and Table 2). However, a portion of the ligand (NB) may compete for another possible binding site IIIA (Sudlow II). Table 3 depicts that the DCM-NB distance at $75^{\circ} \mathrm{C}$ is $2.0 \pm 0.3$ $\mathrm{nm}$. This distance is significantly shorter than that at $25^{\circ} \mathrm{C}$ and is identical to the average distance $(2.0 \mathrm{~nm})$ between the mouth 
TABLE 3: Fluorescence Resonance Energy Transfer between DCM and NB in HSA

\begin{tabular}{cccccccccc}
\hline $\begin{array}{c}\text { temperature } \\
\left({ }^{\circ} \mathrm{C}\right)\end{array}$ & $\begin{array}{c}\text { overlap } \\
\text { integral } \\
\left(\mathrm{M}^{-1} \mathrm{~cm}^{-1} \mathrm{~nm}^{4}\right)\end{array}$ & $\begin{array}{c}R_{0} \\
(\AA)^{a}\end{array}$ & $Q_{\mathrm{D}}{ }^{b}$ & $\begin{array}{c}\tau_{\mathrm{DA}} \\
(\mathrm{ns})^{c}\end{array}$ & $\begin{array}{c}\tau_{\mathrm{D}} \\
(\mathrm{ns})^{d}\end{array}$ & $\tau_{\mathrm{DA}} / \tau_{\mathrm{D}}$ & $E^{e}$ & $\begin{array}{c}R \\
(\AA)\end{array}$ \\
\hline 25 & $2.67 \times 10^{15}$ & 30.22 & 0.0186 & 0.841 & 1.421 & 0.591 & 0.409 & $32 \pm 4$ \\
50 & $2.88 \times 10^{15}$ & 28.02 & 0.0110 & 0.316 & 0.964 & 0.329 & 0.670 & $25 \pm 3$ \\
75 & $3.30 \times 10^{15}$ & 25.46 & 0.0054 & 0.202 & 0.969 & 0.208 & 0.792 & $20 \pm 3$
\end{tabular}

${ }^{a} R_{0}$ is the Förster distance. ${ }^{b} Q_{\mathrm{D}}$ is the quantum yield of the donor in the absence of acceptor. ${ }^{c} \tau_{\mathrm{DA}}$ is the lifetime of the donor in presence of the acceptor. ${ }^{d} \tau_{\mathrm{D}}$ is the lifetime of the donor in absence of the acceptor. ${ }^{e} E$ is the efficiency of energy transfer. ${ }^{f} R$ is the donoracceptor distance.

(Glu450) and hydrophobic bottom (Phe395, Tyr411) of the subdomain IIIA, where the ligand DCM might reside. ${ }^{6,26}$ This result confirms the melting of domain IIB and subsequent binding of NB to domain IIIA at elevated temperatures. It should be noted that the free NB molecules in the buffer as a consequence of the melting of subdomain IIB do not take part in the energy transfer process because of their much larger distance from the donor DCM in the protein.

\section{Conclusion}

In the present study we have characterized various thermally induced unfolded states of a transporter protein HSA by using DLS, CD, and DTA techniques and found a distinct intermediate state at $63{ }^{\circ} \mathrm{C}$ before the protein significantly unfolds beyond $75^{\circ} \mathrm{C}$. We have also investigated the protein binding properties of the ligands, one hydrophobic, DCM, and another cationic, $\mathrm{NB}$, at various temperatures of the host buffer. From the picosecond-resolved fluorescence, solvation relaxation, and polarization-gated anisotropy experiments it is evident that DCM resides in subdomain IIIA of the protein in all of its unfolded states. FRET experiments on the DCM (donor)-NB (acceptor) pair reveal the nature of the binding of the ligands, which are bound simultaneously to HSA at different temperatures. Our study reveals that the cationic probe $\mathrm{NB}$, which resides in subdomain IIB at room temperature, is expelled from its original location at higher temperatures as the subdomain melts at elevated temperatures. Consequently, a portion of the NB population might compete for subdomain IIIA and the other might reside in the bulk buffer. Our experimental studies are important to the future investigations on the molecular recognition of HSA at its various folded states.

Acknowledgment. We thank DST for financial Grant (SR/ FTP/PS-05/2004).

\section{Abbreviations Used}

NB: $\quad$ Nile blue

DCM: 4-(dicyanomethylene)-2-methyl-6-(p-dimethylaminostyryl) $4 \mathrm{H}$-pyran

HSA: human serum albumin

DiISA: 3,5-diiodosalicylic acid

FRET: Förster resonance energy transfer

CD: $\quad$ circular dichroism

DTA: differential thermal analysis

DLS: dynamic light scattering

Supporting Information Available: Detailed description of the experimental methodologies used in the present study. This material is available free of charge via the Internet at http:// pubs.acs.org.

\section{References and Notes}

(1) Kragh, H. U.; Chuang, V. T.; Otagiri, M. Biol. Pharm. Bull. 2002, $25,695-704$

(2) Sudlow, G.; Birkett, D. J.; Wade, D. N. Mol. Pharmacol. 1975, $11,824-832$

(3) Sudlow, G.; Birkett, D. J.; Wade, D. N. Mol. Pharmacol. 1976, $12,1052-1061$

(4) Carter, D. C.; Ho, J. X. Adv. Protein Chem. 1994, 45, 153-203.

(5) Briown, J. R. Albumin Struct., Funct. Uses 1977, 27-51.

(6) He, X. M.; Carter, D. C. Nature 1992, 358, 209-215.

(7) Pico, G. A. Biochem. Mol. Biol. Int. 1995, 36, 1017-1023.

(8) Pico, G. A. Biochem. Mol. Biol. Int. 1996, 38, 1-6.

(9) Pico, G. A. Int. J. Biol. Macromol. 1997, 20, 63-73.

(10) Wetzel, R.; Becker, M.; Behlke, S.; Wite, B.; Bohn, S.; Ebert, B.; Hamaann, H.; Krumbiegel, J.; Lasiman, G. Eur. J. Biochem. 1980, 104, 469-478.

(11) Tayyab, S.; Siddiqui, M. U.; Ahmad, N. Biochem. Educ. 1995, 23, $162-164$.

(12) Lee, J. Y.; Hirose, M. J. Biol. Chem. 1992, 267, 1475314758

(13) Farruggia, B.; Garcia, G.; D'Angelo, C.; Pico, G. Int. J. Biol. Macromol. 1997, 20, 43-51.

(14) Mitra, R. K.; Sinha, S. S.; Pal, S. K. Langmuir 2007, 23, 1022410229

(15) Price, W. S.; Ge, N.-H.; Hong, L.-Z.; Hwang, L.-P. J. Am. Chem. Soc. 1993, 115, 1095-1105.

(16) Kamal, J. K. A.; Zhao, L.; Zewail, A. H. Proc. Natl. Acad. Sci. U.S.A. 2004, 101, 13411-13416.

(17) Flora, K.; Brennan, J. D.; Baker, G. A.; Doody, M. A.; Bright, F. V. Biophys. J. 1998, 75, 1084-1096.

(18) Qiu, W.; Zhang, L.; Okobiah, Y. Y.; Wang, L.; Zhong, D.; Zewail, A. H. J. Phys. Chem. B 2006, 110, 10540-10549.

(19) Douhal, A.; Sanz, M.; Tormo, L. Proc. Natl. Acad. Sci. U.S.A. 2005, 102, 18807-18812.

(20) Zhong, D.; Douhal, A.; Zewail, A. H. Proc. Natl. Acad. Sci. U.S.A 2000, 97, 14056-14061.

(21) Liang, J.-g.; Ai, X.-p.; He, Z.-k.; Xie, H.-y.; Pang, D.-w. Mater Lett. 2005, 59, 2778-2781

(22) Sarkar, R.; Narayanan, S. S.; Palsson, L.-O.; Dias, F.; Monkman, A.; Pal, S. K. J. Phys. Chem. B 2007, 111, 12294-12298.

(23) Narayanan, S. S.; Sarkar, R.; Pal, S. K. J. Phys. Chem. C 2007, $111,11539-11543$

(24) Chen, Q.; Li, D.; Yang, H.; Zhu, Q.; Xu, J.; Zhao, Y. B. Analyst 1999, 124, 901-907.

(25) Mitra, R. K.; Sinha, S. S.; Pal, S. K. J. Fluoresc. 2008, 18, $423-$ 432.

(26) Ghuman, J.; Zunszain, P. A.; Petitpas, I.; Bhattacharya, A. A.; Otagiri, M.; Curry, S. J. Mol. Biol. 2005, 353, 38-52.

(27) Pal, S. K.; Peon, J.; Bagchi, B.; Zewail, A. H. J. Phys. Chem. B 2002, 106, 12376-12395.

(28) Pal, S. K.; Zewail, A. H. Chem. Rev. 2004, 104, 2099-2123.

(29) O'Connor, D. V.; Philips, D. Time Correlated Single Photon Counting; Academic Press: London, 1984.

(30) Lakowicz, J. R. Principles of Fluorescence Spectroscopy; Kluwer Academic/Plenum: New York, 1999.

(31) Takeda, K.; Wada, A.; Yamamoto, K.; Moriyama, Y.; Aoki, K. J. Protein Chem. 1989, 8, 653-659.

(32) Giancola, C.; de Sena, C.; Fessas, D.; Graziano, G.; Barone, G. Int. J. Biol. Macromol. 1997, 20, 193-204.

(33) Sarkar, R.; Shaw, A. K.; Ghosh, M.; Pal, S. K. J. Photochem. Photobiol., B 2006, 83, 213-222.

(34) Peyre, V.; Lair, V.; Andre, V.; le Maire, G.; Kragh-Hansen, U.; le Maire, M.; Moller, J. V. Langmuir 2005, 21, 8865-8875.

(35) Peters, T. J. All about Albumin: Biochemistry, Genetics and Medical Applications; Academic Press: San Diego, CA, 1996.

(36) Pal, S. K.; Mandal, D.; Sukul, D.; Sen, S.; Bhattacharya, K. J. Phys. Chem. B 2001, 105, 1438-1441.

(37) Pal, S. K.; Sukul, D.; Mandal, D.; Sen, S.; Bhattacharyya, K. Chem Phys. Lett. 2000, 327, 91-96.

(38) Shaw, A. K.; Sarkar, R.; Banerjee, D.; Hintschich, S.; Monkman, A.; Pal, S. K. J. Photochem. Photobiol., A 2007, 185, 76-85.

(39) Takeda, K.; Yamamoto, K. J. Protein Chem. 1989, 9, 17-22.

(40) Douhal, A. J. Phys. Chem. 1994, 98, 13131-13137.

(41) Kobayashi, T.; Takagi, Y.; Kandori, H.; Kemnitz, K.; Yoshihara, K. Chem. Phys. Lett. 1991, 180, 416-422.

(42) Dutt, G. B.; Doraiswamy, S.; Periasamy, N.; Venkataraman, B. J. Chem. Phys. 1990, 93, 8498.

(43) Wolber, P. K.; Hudson, B. S. Biophys. J. 1982, 37, 253-262.

(44) Guest, C. R.; Hochstrasser, R. M.; Dupuy, C. G.; Allen, D. J.; Benkovic, S. J.; Millar, D. P. Biochemistry 1991, 30, 8759-8770.

(45) Ludescher, R. D.; Peting, S.; Hudson, B.; Hudson, B. Biophys. Chem. 1987, 28, 59-75.

(46) Das, T. K.; Mazumdar, S. Biophys. Chem. 2000, 86, 15-28. 


\title{
Supporting Information
}

\section{Temperature Dependent Simultaneous Ligand-binding in Human Serum Albumin}

Sudarson Sekhar Sinha, Rajib Kumar Mitra and Samir Kumar Pal*

\author{
Unit for Nano Science \& Technology, \\ Department of Chemical, Biological \& Macromolecular Sciences, \\ S. N. Bose National Centre for Basic Sciences, \\ Block JD, Sector III, Salt Lake, \\ Kolkata 700 098, India
}

*Corresponding Author. Email: skpal@bose.res.in; Fax: 913323353477. 


\section{Experimental methodology:}

Temperature dependent steady-state absorption and emission are measured with Shimadzu spectrophotometer (UV-2450) and Jobin Yvon (Fluoromax-3) fluorimeter respectively with a temperature controller attachment from Julabo (F-32). DLS measurements are done with Nano S Malvern-instrument employing a $4 \mathrm{~mW}$ He-Ne laser $(\lambda=632.8 \mathrm{~nm})$ and equipped with a thermostatted sample chamber. All the scattered photons are collected at $173^{\circ}$ scattering angle at $298 \mathrm{~K}$. The scattering intensity data are processed using the instrumental software to obtain the hydrodynamic diameter ( $\mathrm{dH})$ and the size distribution of the scatterer in each sample. The instrument measures the time dependent fluctuation in the intensity of light scattered from the particles in solution at a fixed scattering angle. Hydrodynamic diameters $(\mathrm{dH})$ of the particles are estimated from the intensity auto-correlation function of the time-dependent fluctuation in intensity. $\mathrm{dH}$ is defined as,

$$
\mathrm{d}_{\mathrm{H}}=\mathrm{kT} / 3 \pi \eta \mathrm{D}
$$

where $\mathrm{k}=$ Boltzmann constant, $\mathrm{T}=$ absolute temperature, $\eta=$ viscosity and $\mathrm{D}=$ translational diffusion coefficient. In a typical size distribution graph from the DLS measurement, Xaxis shows a distribution of size classes in $\mathrm{nm}$, while the $\mathrm{Y}$-axis shows the relative intensity of the scattered light. The DTA is done in a Diamond TG/DTA instrument from Perkin Elmer. The circular dichroism (CD) measurements are done in a JASCO-815 spectropolarimeter with an attachment for the temperature dependent measurements (Peltier). The secondary structural data of the CD spectra are analyzed using CDNN software. 
Fluorescence transients are measured and have been fitted by using commercially available spectrophotometer (LifeSpec-ps) from Edinburgh Instrument, U.K (excitation wavelength $409 \mathrm{~nm}, 80$ ps instrument response function (IRF)) with an attachment (Julabo F-32) for temperature dependent studies. The observed fluorescence transients are fitted by using a nonlinear least square fitting procedure to a function $\left(X(t)=\int_{0}^{t} E\left(t^{\prime}\right) R\left(t-t^{\prime}\right) d t^{\prime}\right)$ comprising of convolution of the IRF $(E(t))$ with a sum of exponentials $\left(\mathrm{R}(\mathrm{t})=\mathrm{A}+\sum_{\mathrm{i}=1}^{\mathrm{N}} \mathrm{B}_{\mathrm{i}} \mathrm{e}^{-\mathrm{t} / \tau_{\mathrm{i}}}\right)$ with pre-exponential factors $\left(\mathrm{B}_{\mathrm{i}}\right)$, characteristic lifetimes $\left(\tau_{\mathrm{i}}\right)$ and a background (A). Relative concentration in a multi-exponential decay is finally expressed as; $c_{n}=\frac{B_{n}}{\sum_{i=1}^{N} B_{i}} \times 100$. The quality of the curve fitting is evaluated by reduced chi-square and residual data.

To construct time-resolved emission spectra (TRES) we follow the technique described in references ${ }^{1,2}$. As described above the emission intensity decays are analyzed in terms of the multi-exponential model,

$$
\mathrm{I}(\lambda, \mathrm{t})=\sum_{\mathrm{i}=1}^{\mathrm{N}} \alpha_{i}(\lambda) \exp \left[-\mathrm{t} / \tau_{\mathrm{i}}(\lambda)\right]
$$

where $\alpha_{i}(\lambda)$ are the pre-exponential factors, with $\Sigma \alpha_{i}(\lambda)=1.0$. In this analysis, we compute a new set of intensity decays, which are normalized so that the time-integrated intensity at each wavelength is equal to the steady-state intensity at that wavelength. Considering $F(\lambda)$ to be the steady-state emission spectrum, we calculate a set of $H(\lambda)$ values using, 


$$
H(\lambda)=\frac{F(\lambda)}{\int_{0}^{\infty} \mathrm{I}(\lambda, \mathrm{t}) \mathrm{dt}}
$$

which for multi-exponential analysis becomes,

$$
\mathrm{H}(\lambda)=\frac{\mathrm{F}(\lambda)}{\sum_{i} \alpha_{i}(\lambda) \tau_{i}(\lambda)}
$$

Then, the appropriately normalized intensity decay functions are given by,

$$
\mathrm{I}^{\prime}(\lambda, \mathrm{t})=\mathrm{H}(\lambda) \mathrm{I}(\lambda, t)=\sum_{\mathrm{i}=1}^{\mathrm{N}} \alpha_{\mathrm{i}}^{\prime}(\lambda) \exp \left[-\mathrm{t} / \tau_{\mathrm{i}}(\lambda)\right]
$$

where $\alpha_{i}^{\prime}(\lambda)=H(\lambda) \alpha_{i}(\lambda)$. The values of $I^{\prime}(\lambda, t)$ are used to calculate the intensity at any wavelength and time, and thus the TRES. The values of the emission maxima and spectral width are determined by nonlinear least-square fitting of the spectral shape of the TRES. The spectral shape is assumed to follow a lognormal line shape ${ }^{2}$,

$$
\mathrm{I}(\bar{v})=\mathrm{I}_{0} \exp \left\{-\left[\ln 2\left(\frac{\ln (\alpha+1)}{\mathrm{b}}\right)^{2}\right]\right\}
$$

with $\alpha=\frac{2 \mathrm{~b}\left(\bar{v}-\overline{v_{\max }}\right)}{\mathrm{b}}>-1$, where $\mathrm{I}_{0}$ is amplitude, $\bar{v}_{\max }$ is the wavenumber of the emission maximum and spectral width is given by $\Gamma=\Delta\left[\frac{\sinh (b)}{b}\right]$

The terms $\mathrm{b}$ and $\Delta$ are asymmetry and width parameters respectively. The equation (6) reduces to a Gaussian function for $b=0$. 
The Förster distance $\left(\mathrm{R}_{0}\right)$ of donor-acceptor pair is given by,

$$
\mathrm{R}_{0}=0.211\left[\kappa^{2} \mathrm{n}^{-4} \mathrm{Q}_{\mathrm{D}} \mathrm{J}(\lambda)\right]^{1 / 6} \quad(\text { in } \AA \text { ) }
$$

where $\kappa^{2}$ is a factor describing the relative orientation in space of the transition dipoles of the donor and acceptor. For donor and acceptors that randomize by rotational diffusion prior to energy transfer, the magnitude of $\kappa^{2}$ is assumed to be $2 / 3$. In the present study the same assumption has been made. The refractive index $(n)$ of the medium is assumed to be 1.4. $Q_{\mathrm{D}}$ is the quantum yield of the donor in the absence of acceptor. J $(\lambda)$, the overlap integral, which expresses the degree of spectral overlap between the donor emission and the acceptor absorption, is given by,

$$
J(\lambda)=\frac{\int_{0}^{\infty} F_{D}(\lambda) \varepsilon(\lambda) \lambda^{4} d \lambda}{\int_{0}^{\infty} F_{D}(\lambda) d \lambda}
$$

where $F_{D}(\lambda)$ is the fluorescence intensity of the donor in the wavelength range of $\lambda$ to $\lambda+\mathrm{d} \lambda$ and is dimensionless. $\varepsilon(\lambda)$ is the extinction coefficient (in $\mathrm{M}^{-1} \mathrm{~cm}^{-1}$ ) of the acceptor at $\lambda$. If $\lambda$ is in $\mathrm{nm}$, then $\mathrm{J}(\lambda)$ is in units of $\mathrm{M}^{-1} \mathrm{~cm}^{-1} \mathrm{~nm}^{4}$. Once the value of $\mathrm{R}_{0}$ is known, the donor-acceptor distance $(R)$ can easily be calculated using the formula,

$$
\mathrm{R}^{6}=\left[\mathrm{R}_{0}{ }^{6}(1-\mathrm{E})\right] / \mathrm{E}
$$

Here $\mathrm{E}$ is the efficiency of energy transfer. The transfer efficiency is measured using the relative fluorescence intensity of the donor in the absence $\left(\mathrm{F}_{\mathrm{D}}\right)$ and presence $\left(\mathrm{F}_{\mathrm{DA}}\right)$ of the acceptor. The efficiency $\mathrm{E}$ is also calculated from the lifetimes under these respective conditions $\left(\tau_{\mathrm{D}} \text { and } \tau_{\mathrm{DA}}\right)^{1}$.

$$
\mathrm{E}=1-\left(\tau_{\mathrm{DA}} / \tau_{\mathrm{D}}\right)
$$




\section{References}

(1) Lakowicz, J. R. Principles of fluorescence spectroscopy; Kluwer Academic/Plenum: New York, 1999.

(2) Horng, M. L.; Gardecki, J. A.; Papazyan, A.; Maroncelli, M. J. Phys. Chem. 1995, 99, 17311-17337. 